\title{
Comparative estimation of the efficiency of ten drugs against two severe coccidioses in the rabbit
}

\author{
P. COUDERT \\ Station de pathologie aviaire, \\ Contre de Recherches de Tours, I.N.R.A., Nouzilly, $383^{80}$ Monnaie (France)
}

The efficiency of ten substances known for being active against Emeria was estimated and compared in the case of two coccidioses in the rabbit induced by $E$. intestinalis and $E$. pellerdyi. The animals received the feed admixed with the drug, five days prior to the experimental infestation with $5^{\circ}$ ooo oocysts of each species. The parameters studied were weight gain, feed intake and mortality rate.

The species of Emeria did not exhibit the same susceptibility towards the action of the different drugs. The latter can be ranked in 3 categories for each coccidium: $\mathrm{F}$ = efficient; $\mathrm{R}=$ relatively efficient; $\mathrm{I}$ : insufficiently efficient or inefficient. The results are summarized in the table below:

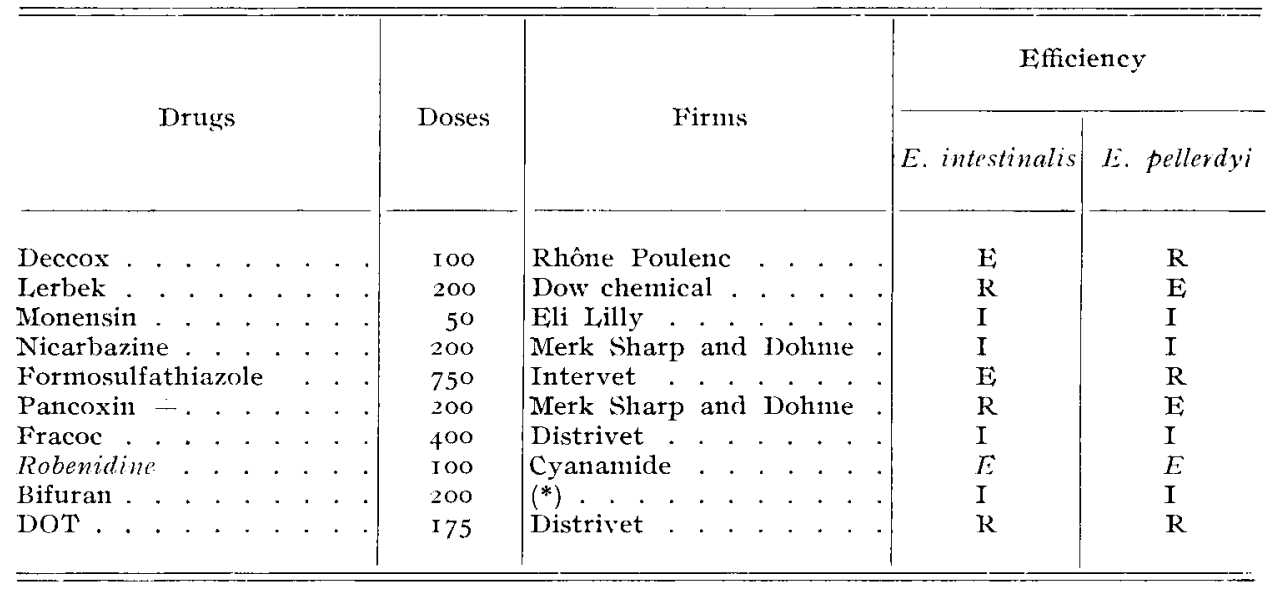

$\left(^{*}\right)=100 \mathrm{ppm}$ nitrofurazone + Ioo ppm futazolidone. 